\title{
Uso e gestão do território em áreas de livre acesso no Amazonas, Brasil
}

\author{
Samantha Aquino PEREIRA ${ }^{1}$, Nidia Noemi FABRÉ ${ }^{2}$ \\ RESUMO \\ As comunidades tradicionais da várzea amazônica ocupam uma variedade de ambientes adaptadas às variaçóes sazonais impostas \\ pelo pulso de inundação, o que reflete no desenvolvimento de estratégias de uso e manejo dos recursos naturais. Neste trabalho \\ foi avaliada a territorialidade dessas comunidades, observando a relação custo-beneficio da exploração pesqueira, madeireira e \\ agrícola e sua relação com os conflitos sócioambientais oriundos da exploração de recursos naturais de uso comum em áreas \\ de livre acesso. As entrevistas foram realizadas entre agosto de 2003 e novembro de 2004, atingindo $50 \%$ de cada comunidade \\ estudada, na Costa do Canabuoca, município de Manacapuru. As variáveis utilizadas para avaliar a territorialidade foram: \\ rendimento produtivo, econômico e distância percorrida para a exploração. Foram espacializados os ambientes usados para a \\ exploração por meio do Sistema de Informação Geográfica (SIG). Os resultados indicam que a pesca é a atividade geradora de \\ conflitos e territorialidade, produto da interação entre distribuição, disponibilidade, produtividade dos pesqueiros e organização \\ político-institucional dos moradores, que se reflete na relação custo-beneficio.
}

PALAVRAS-CHAVE: Amazônia, várzea, territorialidade humana, áreas de livre acesso.

\section{Use and management of territory in areas with open acess in Amazonas, Brazil}

\begin{abstract}
The traditional communities of the Amazon floodplain occupy a large variety of seasonal environments and have adapted to the variations determined by the flood pulse, which is reflected in the development of their resource managment strategies. In this work the territoriality of these communities was evaluated by observing the cost-benefit relationship for fisheries, forests and agricultural exploration to social and environmental conflicts originating from the explotation of natural resources of common property in areas of open access. Interviews were conducted between August of 2003 and November of 2004, with the head of family in $50 \%$ of each community studied, on the coat of Canabouca, district of Manacapuru. The variables used to evaluate territoriality were: production, revenue and distance traveled. The areas of exploitation were analyzed using Global Information System (GIS). The results indicated that fishing activities generate conflicts and territoriality, which is the product of the interaction between distribution, avaliability and productivity of fishing areas and the political organization of the communities, that is reflected in the cost-benefit relationship.
\end{abstract}

KEYSWORDS: Amazon, floodplain, human territoriality, open access areas

\footnotetext{
1 Instituto de Desenvolvimento Sustentável Mamirauá

${ }^{2}$ Universidade Federal de Alagoas - Instituto de Ciências Biológicas e da Saúde (ICBS). Laboratório de Ecologia de Peixes e Pesca. Rua Aristeu de Adrade 452. Farol. Maceió-AL. CEP: 57021-09. e-mail: nidia.fabre@pq.cnpq.br
} 


\section{INTRODUÇÃO}

A exploração dos recursos naturais e sua distribuição espacial, associado a uma ação coletiva voluntária que busca o controle do desenvolvimento do território, representam acepções da noção de gestão do território (Godard, 1996). Dentro deste contexto, a territorialidade humana representa uma base conceitual que pode subsidiar a gestão ambiental do território, visto que a mesma é estabelecida, pelos usuários, como forma de controlar e defender o espaço e os recursos de uma determinada área, por meio da mobilização social e política-institucional.

Dyson-Hudson \& Smith (1978) abordam a relação território - ambiente por meio da análise de custos e benefícios da defesa do território. No Brasil, Seixas \& Begossi (1998) e Begossi (1995 e 2001) têm analisado a territorialidade humana verificando o tempo gasto na defesa e divisão do território, principalmente associado à exploração pesqueira. No cenário amazônico, a gestão do território, conservação dos recursos naturais e a territorialidade foram abordadas por McDaniel (1997), McGrafh et al. (1996) e Pereira (1999). Recentemente, Ribeiro \& Fabré (2003) propuseram uma alternativa para a gestão ambiental, denominada Sistemas Abertos Sustentáveis - SAS. Esses sistemas foram propostos para áreas de várzea de livre acesso, as quais não possuem direitos de propriedade bem definidos e o conseqüente acesso aos recursos naturais e aos bens e serviços ecológicos pelos grupos sociais estabelecidos na área focal de interesse. Contudo, àquele pressupõe uma variação ao regime de propriedade comunal, no sentido que são estabelecidos normas e critérios de uso dos recursos naturais, sendo permitido o acesso a usuários eventuais, externos ao sistema, desde que obedeçam as normas estabelecidas. O território de propriedade aberta comunal representa uma unidade de co-gestão, funcionando como um sistema integrado, visto que considera a dinâmica indivisível dos recursos naturais, dos serviços ambientais associados e dos processos socioeconômicos que levaram a reprodução social dos grupos envolvidos na manutenção desse território (Fabré et al. 2006).

No processo histórico de ocupação da várzea, as populações ribeirinhas amazônicas adaptaram-se às fortes flutuaçōes, impostas pela dinâmica de inundação, fazendo uso integrado, tanto dos diversos ambientes de várzea como dos adjacentes na terra firme. Dentro deste contexto, o objetivo do presente trabalho foi avaliar a territorialidade humana, em comunidades ribeirinhas da Amazônia Central, considerando a relação custo-beneficio da exploração pesqueira, madeireira e agrícola e sua relação com os conflitos sócioambientais oriundos da exploração de recursos naturais de uso comum em áreas de livre acesso.

\section{MATERIAL E MÉTODOS}

A área de estudo localiza-se no município de Manacapuru, no centro da região Fisiográfica Solimões/Tefé (Figura 1), especificamente na Costa do Canabuoca, onde está localizado o Sistema lacustre do Cururu.

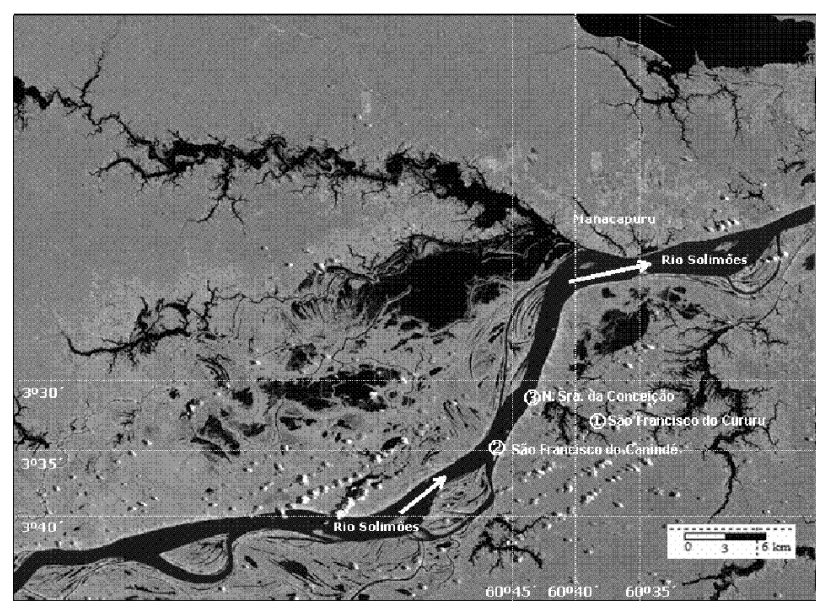

Figura 1 - Mapa da área de estudo, destacando as três comunidades estudadas. Imagens LANDSAT cedida pelo laboratório de sensoriamento Remoto da Universidade Federal do Amazonas.

O sistema estudado tem uma área de $35 \mathrm{~km}^{2}$, está localizado entre o rio Solimóes e o Paraná do Cururu. Compóem este sistema, um lago dendrítico de terra firme (lago do Cururu) e um complexo de pequenos lagos de várzea (Rei, Reizinho e Reis Grande). Um total de onze comunidades está distribuído no Sistema do Cururu, principalmente, na Costa do Canabuoca (Fabré et al. 2003). Desse total foram estudadas as comunidades, Nossa Senhora da Conceição $\left(03^{\circ} 28^{\prime \prime} 2^{\prime}\right.$ S, 60 44" 21' W), São Francisco de Canindé (03 32" 8' S $60^{\circ} 47^{\prime \prime} 38^{\prime}$ W), ambas localizadas na costa, e São Francisco do Cururu (03 30" 25,7’ S 60 41" 13,7’ W), localizada na margem do lago Cururu.

A coleta de informações foi realizada em agosto de 2003, janeiro, junho e novembro de 2004, totalizando 4 meses, referentes às diferenciaçôes no nível do rio. Foram entrevistados $50 \%$ dos chefes de família das três comunidades estudadas $(\mathrm{n}=33)$. As variáveis utilizadas para avaliar a territorialidade foram: nome e localização geográfica do ambiente de exploração; distância da comunidade ao local de extração; tempo gasto até o local de extração; época de extração (seca e cheia) e rendimento econômico e produtivo da pesca, agricultura e extração madeireira. Estes últimos foram calculados como o quociente entre a quantidade capturada/ produzida/extraída (em $\mathrm{kg}$ para a pescaria e agricultura e $\mathrm{m}^{3}$ para a madeira) por atividade e o esforço de trabalho medido como o número de produtores, pescadores ou madeireiros, conforme a atividade analisada. No caso da pesca, o esforço foi 
multiplicado pelo tempo em dias investido na captura. Para o rendimento agrícola, a quantidade produzida representou o total de produtos colhidos durante o ano $(\mathrm{em} \mathrm{kg})$, sendo o número de agricultores contabilizado pelo tamanho médio da família, visto que a produção agrícola na área estudada é de tipo familiar (Noda, 1997; Parente, 2003; Menezes, 2004).

O rendimento econômico representa o faturamento bruto com a comercialização dos produtos, estimado a partir da soma do preço declarado da venda dos produtos.

Para estudo das relações sociais entre os grupos domésticos foram consideradas as informaçôes relativas a: tempo de moradia no local, mobilidade espacial, presença de conflitos e organização político institucional, avaliada pela existência e participação em associações locais. Por último, a atitude socioambiental foi analisada a partir do conhecimento do instrumento de gestão comunitária local, por meio da participação nas reuniōes e o entendimento sobre a elaboração e implementação do mesmo para o cuidado e uso responsável dos recursos naturais das áreas: os Acordos de Uso Integrado ${ }^{1}$

Para a espacialização das informaçōes sobre a infra-estrutura comunitária, diversidade ambiental e as formas de uso dos recursos foram utilizadas duas estratégias metodológicas. Uma referente à elaboração, junto aos líderes comunitários, de mapas cognitivos (Nogueira, 2001) e a segunda foi à utilização de técnicas de SIG (Sistema de Informação Geográfica), tendo como base imagens JERS-1-SAR: maio/julho, 1996 (copyright 1992-1998 by NASDAMITI) e Base cartográfica do Instituto de Proteção do Amazonas -IPAAM. Sobre estas bases foram plotadas as coordenadas geográficas dos ambientes utilizados pelos comunitários para produção agrícola, pesqueira e madeireira.

\section{RESULTADOS}

1. ATIVIDADES PRODUTIVAS E USO DOS RECURSOS NATURAIS: AMBIENTES, DISTÂNCIAS, RENDIMENTOS PRODUTIVO E ECONÔMICO.

\section{AMBIENTES UTILIZADOS}

A agricultura é praticada, principalmente, no período de seca nos ambientes de restinga da várzea alta e baixa pelas comunidades São Francisco do Canindé e Nossa Senhora da Conceição e na terra firme pela comunidade de São Francisco do Cururu, sendo os ambientes mais utilizados: a restinga da Costa do Canabuoca $(51,75 \%)$ e a ilha homônima $(18,42 \%)$. A extração de madeira é realizada durante a cheia, período no qual existem condiçôes para o transporte. Os ambientes de várzea alta, como a restinga do paraná do Cururu (62,50\%), a restinga do lago Cururu (25\%) e as áreas de terra firme, distantes em média $6 \mathrm{~km}$ da costa $(12,50 \%)$ são os ambientes mais explorados para a extração de madeira. $\mathrm{Na}$ pesca foi verificada uma riqueza de ambientes utilizados, contudo sempre há uma relação com o período de subida e descida das águas, que determina a disponibilidade e acessibilidade aos ambientes, principalmente os lagos de várzea e o igapó. O lago Cururu $(64,71 \%)$ e o rio Solimões $(17,65 \%)$ são os ambientes mais procurados durante a seca, e na cheia o lago Cururu (56,25\%) e o igapó do lago Cururu (15,63\%) (Tabela 1).

Tabela 1 - Diversidade de ambiente e freqüência relativa de uso por atividade produtiva no sistema do Cururu, Costa do Canabuoca, Manacapuru, Amazonas.

\begin{tabular}{|c|c|c|c|c|c|c|}
\hline \multirow{2}{*}{ Ambientes } & \multicolumn{2}{|c|}{$\begin{array}{l}\text { Produção } \\
\text { Agrícola }\end{array}$} & \multicolumn{2}{|c|}{$\begin{array}{l}\text { Produção } \\
\text { Pesqueira }\end{array}$} & \multicolumn{2}{|c|}{$\begin{array}{l}\text { Produção } \\
\text { Madeireira }\end{array}$} \\
\hline & Seca & Cheia & Seca & Cheia & Seca & Cheia \\
\hline ilha do Canabuoca & $18,42 \%$ & & & & & \\
\hline $\begin{array}{l}\text { restinga do } \\
\text { Canabuoca }\end{array}$ & $51,75 \%$ & & & & & \\
\hline $\begin{array}{l}\text { restinga do lago } \\
\text { Cururu }\end{array}$ & $4,39 \%$ & & & & & $62,50 \%$ \\
\hline $\begin{array}{l}\text { restinga do paraná } \\
\text { do Cururu }\end{array}$ & $6,14 \%$ & & & & & $25,00 \%$ \\
\hline $\begin{array}{l}\text { restinga do igarapé } \\
\text { do Furão }\end{array}$ & $5,26 \%$ & & & & & \\
\hline terra Firme & $3,51 \%$ & & & & & $12,50 \%$ \\
\hline $\begin{array}{l}\text { restinga do igarapé } \\
\text { do Caetano }\end{array}$ & $3,51 \%$ & & & & & \\
\hline $\begin{array}{l}\text { restinga do paraná } \\
\text { Miranda }\end{array}$ & $1,75 \%$ & & & & & \\
\hline lago Cururu & & & $64,71 \%$ & $56,25 \%$ & & \\
\hline lago do Reizinho & & & $2,94 \%$ & & & \\
\hline lago dos Reis & & & $2,94 \%$ & & & \\
\hline $\begin{array}{l}\text { lago dos Reis } \\
\text { Grande }\end{array}$ & & & $2,94 \%$ & & & \\
\hline paraná do Cururu & & & $8,82 \%$ & $9,38 \%$ & & \\
\hline rio Solimões & & & $17,65 \%$ & $9,38 \%$ & & \\
\hline $\begin{array}{l}\text { igapó do lago } \\
\text { Cururu }\end{array}$ & & & & $15,63 \%$ & & \\
\hline $\begin{array}{l}\text { igapó do paraná do } \\
\text { Cururu }\end{array}$ & & & & $9,38 \%$ & & \\
\hline
\end{tabular}

\section{DISTÂNCIAS PERCORRIDAS}

As distâncias percorridas pelos pescadores das comunidades Canindé e Conceição, são superiores as observadas para a comunidade do Cururu. Na seca, os pesqueiros ficam ainda mais distantes que na cheia para os pescadores do

\footnotetext{
1 Acordo de Uso Integrado: instrumento de co-gestão ambiental que permite estabelecer de forma participativa as regras de uso responsável dos recursos naturais, em áreas de livre acesso (Ribeiro \& Fabré, 2003).
} 
São Francisco do Canindé e Nossa Senhora da Conceição, ocorrendo uma alta variação em torno da distância média percorrida pelos pescadores dessas comunidades, fato que está relacionado à diversidade de pesqueiros explorados, exemplificado, por exemplo, pelo lago do Reis Grande, distante a $8 \mathrm{~km}$ da comunidade, no entanto, o rio Solimões fica a meio quilômetro de distância da comunidade São Francisco do Canindé (Tabela 2).

Tabela 2 - Locais de pesca explorados por comunidade, indicando a distância pesqueira-comunidade durante a seca e cheia e a média e desvio padrão por período.

\begin{tabular}{|c|c|c|c|}
\hline Comunidade & Locais de pesca & $\begin{array}{c}\text { Média da } \\
\text { distância na } \\
\text { Seca }(\mathrm{km})\end{array}$ & $\begin{array}{c}\text { Média da } \\
\text { distância na } \\
\text { Cheia (km) }\end{array}$ \\
\hline \multirow{3}{*}{ Cururu } & lago Cururu & 0,138 & 0,650 \\
\hline & lago Cururu (poço) & 0,133 & - \\
\hline & igapó do lago Cururu & - & 0,395 \\
\hline Média & & 0,135 & 0,523 \\
\hline Desvio padrão & & 0,003 & 0,180 \\
\hline \multirow{7}{*}{ Canindé } & lago Cururu & 1,000 & 0,900 \\
\hline & lago do Reisinho & 2,000 & - \\
\hline & lago dos Reis & 2,000 & - \\
\hline & lago dos Reis Grande & 8,000 & - \\
\hline & paraná do Cururu & 1,100 & 1,000 \\
\hline & rio Solimões & 0,472 & 0,100 \\
\hline & $\begin{array}{c}\text { igapó do paraná do } \\
\text { Cururu }\end{array}$ & - & 1,200 \\
\hline Média & & 1,498 & 0,800 \\
\hline Desvio padrão & & 2,551 & 0,483 \\
\hline \multirow{3}{*}{ Conceição } & lago Cururu & 2,556 & 2,143 \\
\hline & rio Solimões & 0,500 & 0,150 \\
\hline & igapó do lago Cururu & - & 1,000 \\
\hline Média & & 1,578 & 1,098 \\
\hline Desvio padrão & & 1,028 & 1,000 \\
\hline
\end{tabular}

\section{RENDIMENTO PRODUTIVO E ECONÔMICO}

Em relação ao rendimento da produção por ambiente e por comunidade, da agricultura, medido como quilograma $(\mathrm{kg})$ de produtos agrícolas produzido pelo grupo doméstico foi observado, que as comunidades da costa (Canindé e Conceição) apresentaram rendimentos altos e semelhantes aos diversos ambientes de restinga da várzea, tais como a do Canabuoca e do paraná do Cururu. No caso da comunidade do Cururu localizada em ambiente de terra firme, se destaca a alta produção da restinga do igarapé do Caetano (Figura 2a).

No caso da madeira, são poucos os ambientes utilizados, três comunidades exploram a terra firme, mas chamam a atenção os maiores rendimentos obtidos pelos madeireiros das comunidades do Canindé, na floresta de várzea encontrada na restinga do paraná do Cururu e do Canabuoca (Figura 2b). A extração de pescado, durante a seca, pelas comunidades do Cururu e Conceição, apresentou os maiores rendimentos no lago Cururu, diferente da comunidade São Francisco do Canindé cujos rendimentos são oriundos do sistema de lagos de várzea Reizinho e Reis Grande (Figura 2c). Durante a cheia, o lago Cururu é espaço produtivo e comum a todos os pescadores. É importante destacar que os pescadores da Conceição pescam no lago Cururu em ambos os períodos, mesmo em detrimento da maior distância desse lago na seca (Figuras 2 c e d e Tabela 2).

Quanto ao custo-benefício da exploração pesqueira, verificado pela relação entre a distância percorrida para a exploração e o rendimento produtivo e econômico por pescador, observa-se que todos os pesqueiros apresentam rendimento produtivo, variando em $150 \mathrm{~kg}$, com exceção do lago do Cururu, com $400 \mathrm{~kg}$ na seca. Na cheia, o igapó do lago Cururu é mais produtivo, em torno de $900 \mathrm{~kg}$ para a comunidade do S. F. do Canindé. As distâncias percorridas para a exploração na maioria dos pesqueiros variam entre $0,1 \mathrm{~km}$ a $2 \mathrm{~km}$, sendo maiores na seca. Por outro lado, vemos que há uma relação direta entre o rendimento econômico e produtivo, com exceção dos lagos Reizinho e Reis Grande, explorados pelos pescadores do Canindé, que são os pesqueiros mais longínquos, com baixos rendimentos produtivos, mas com os maiores rendimentos econômicos (Figura 3a , b, c e d). Isso pode ser atribuído à pesca de pirarucu praticada na seca, cujo preço por quilograma, em média supera três vezes o valor dos Characídeos, como curimatã, branquinha ou pacu.

Para a extração madeireira, a comunidade São Francisco do Cururu apresentou as menores distâncias e maior rendimento. Diferente da comunidade Conceição, que percorre grandes distâncias e apresenta baixo rendimento e da Canindé, que mesmo percorrendo grandes distâncias ainda apresenta altos rendimentos (Figura 4).

\section{ESPACIALIZAÇÃO E SOBREPOSIÇÃO DOS AMBIENTES UTILIZADOS}

A sobreposição territorial de uso do recurso pesqueiro foi verificada no lago Cururu e classificada como alta, pela utilização comum das três comunidades estudadas, assim como, a terra-firme do lago Cururu é para extração madeireira. Ambientes, como a restinga do paraná do Cururu, apresentaram uma sobreposição média, já que é utilizado por duas comunidades: Canindé e Conceição (Figura 5). É importante destacar que as áreas de cultivo localizadas nas restingas (várzea alta) do Canabuoca, denominada localmente como costa, são utilizadas para a agricultura por todas as comunidades localizadas nesses ambientes de várzea e representam áreas delimitadas em terrenos públicos e não coletivos, uma vez que as áreas de várzea são patrimônio da união, cujo uso é cedido as famílias locais, que os toma como 


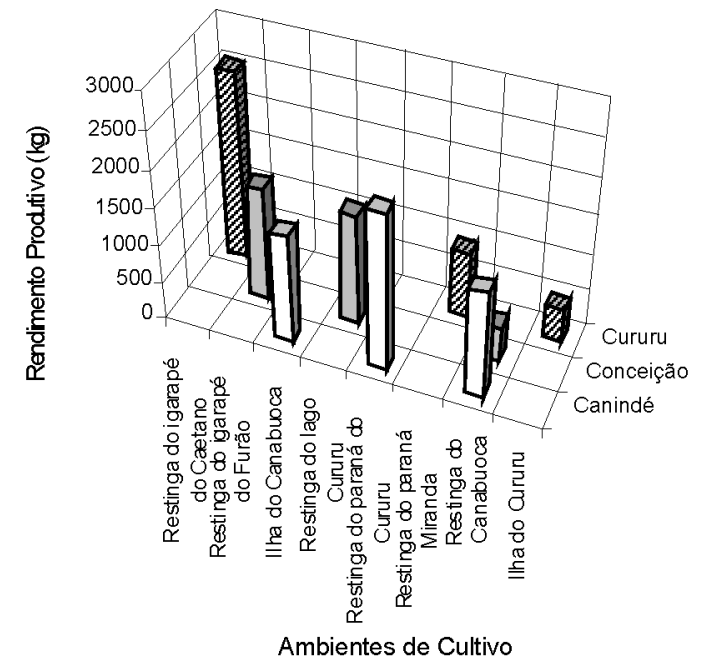

$\mathbf{a}$

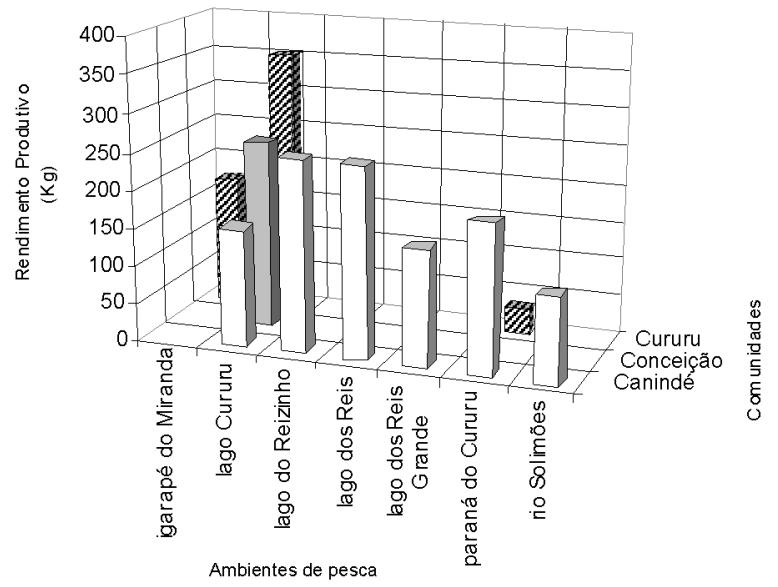

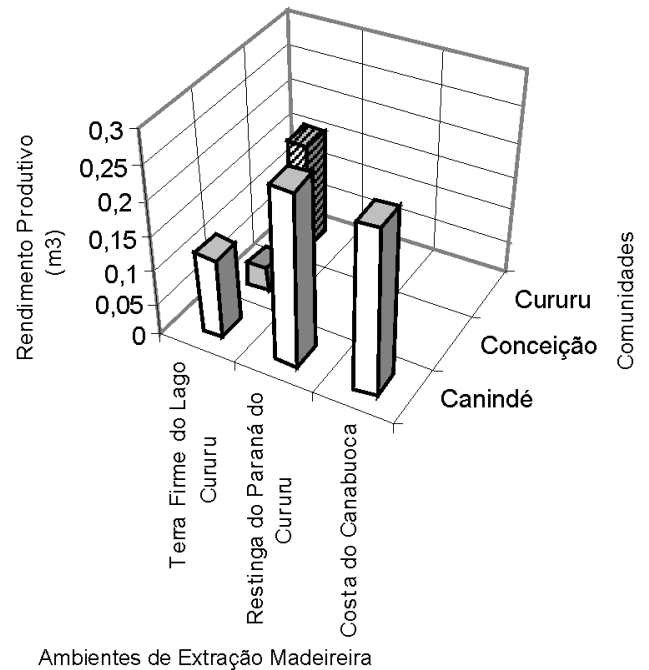

b

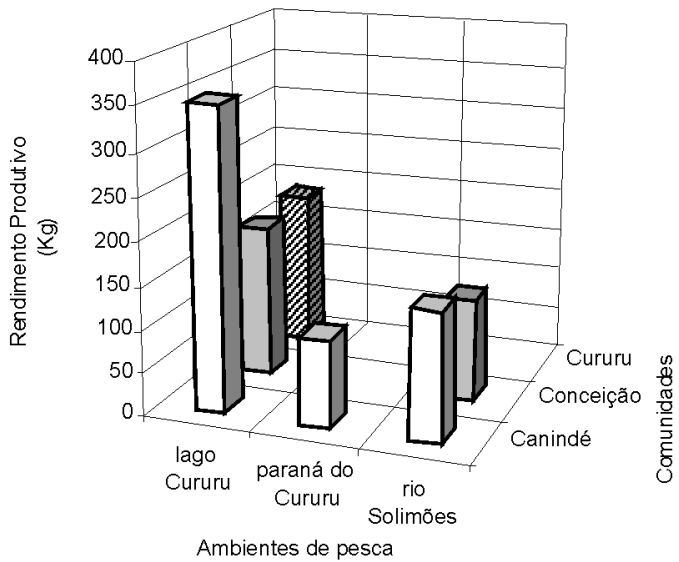

d

Figura 2. - Rendimento Produtivo (kg) por ambiente da agricultura (a), da extração madeireira (b) e da pesca para a seca (c) e cheia (d).

propriedade privada. Verificou-se ainda a preferência pelo cultivo próximo às residências, em média de 0,01 a 0,02 $\mathrm{km}$, e que apresentam alta produtividade, portanto não há sobreposição.

Tanto a extração de madeira quanto de peixe propiciam comportamento territorial, denotado pelo uso exclusivo e apropriação histórica dos comunitários acompanhados no presente estudo, contudo a pesca por ser uma atividade extrativa praticada sobre um recurso de uso comum e por um maior número de pessoas é a atividade que se destaca, somada a geração de conflitos, principalmente, pelos moradores do entorno do lago, comunidade do Cururu, e de fora do lago, principalmente com a comunidade Conceição. A expansão e diversificação dos pesqueiros na cheia atenuam os conflitos em relação à seca. Durante a seca a busca pelos pesqueiros é maior, indicada pela expansão do raio total explorado, pois são utilizados pesqueiros mais distantes, diminuindo o percentual de pesqueiros localizados entre 0,1 e 1,0 km (Figura 6). Também se pode verificar que na cheia há maior diversidade e número de pesqueiros mais próximos às residências, até meio quilômetro de distância, cenário que se modifica na seca quando os pesqueiros se tornam menos disponíveis, mais dispersos e mais produtivos.

O tempo de moradia em média é de 28 anos, entretanto, verificou-se que a comunidade São Francisco do Canindé possui um processo de formação mais recente que as demais. As comunidades são constituídas, principalmente, por indivíduos que vieram de localidades fora de Manacapuru ou próximas à área de estudo. Os conflitos existentes na área estão relacionados com o não cumprimento do Acordo, principalmente vinculados à prática da pesca. Apesar desses conflitos estarem relacionados ao Acordo, observou-se alto 
a
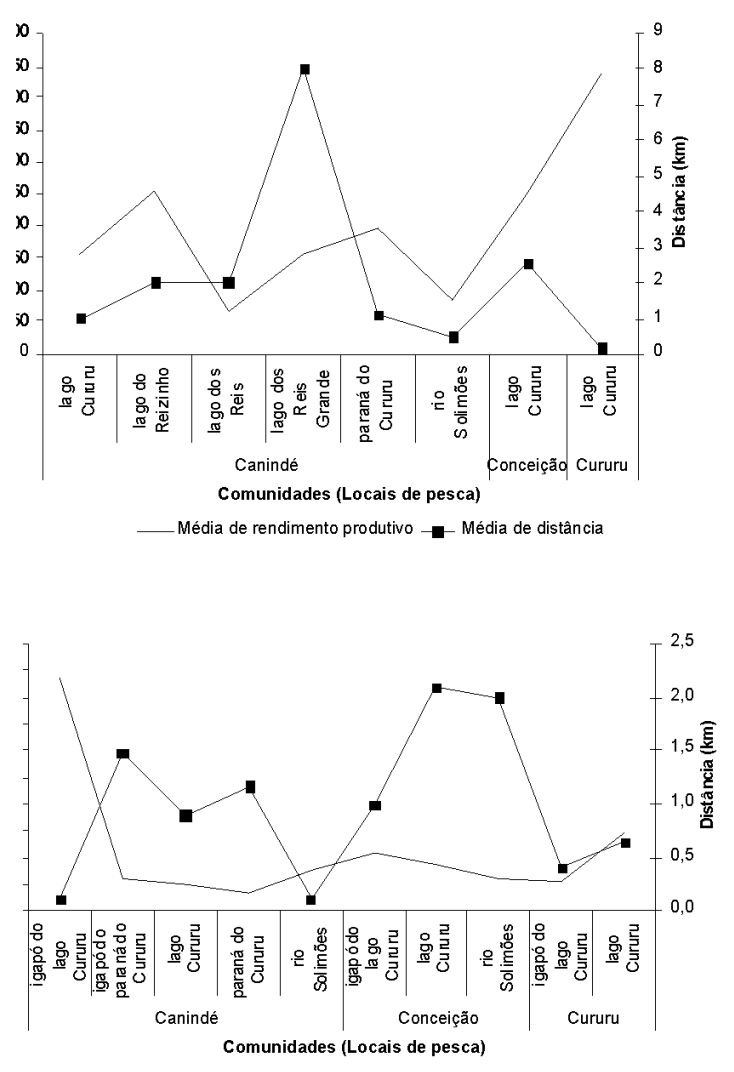

— Média de Rendimento Produtivo - Média de Distância b

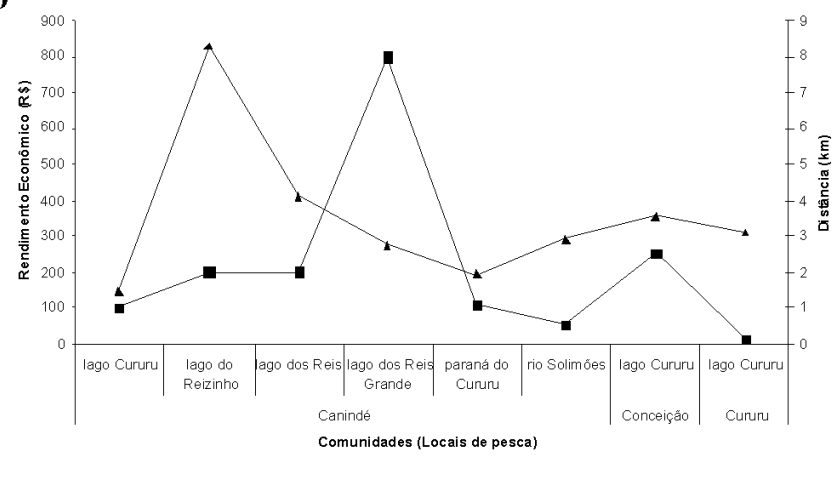

d

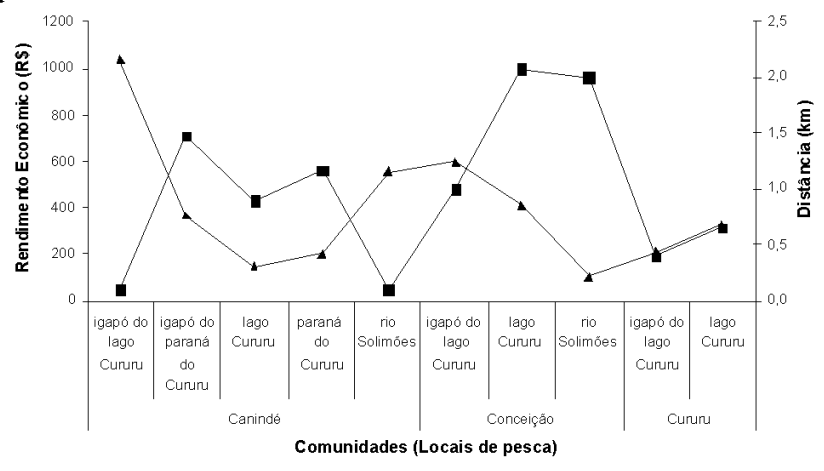

Figura 3 - Rendimento produtivo, econômico e distância percorrida pelo pescador na seca (a e b) e na cheia (c e d).

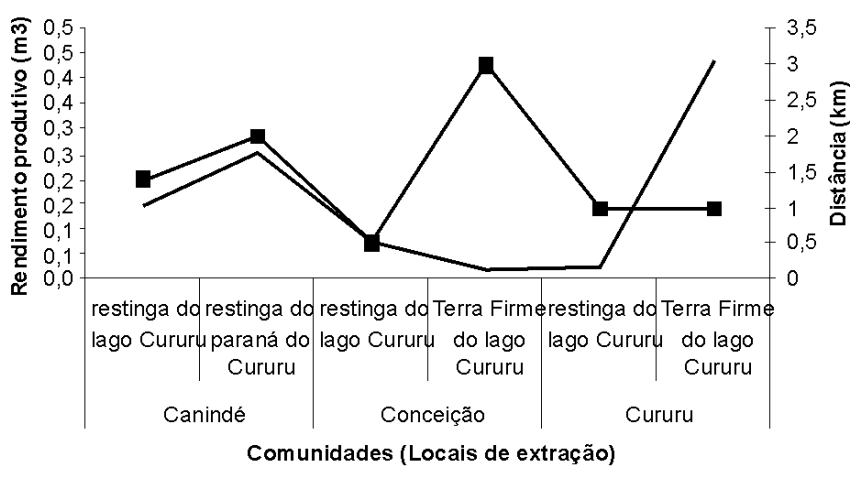

— Média de Rendimento Produtivo - Média de Distância

Figura 4 - Rendimento produtivo e distância percorrida pelos comunitários para da extração madeireira. 


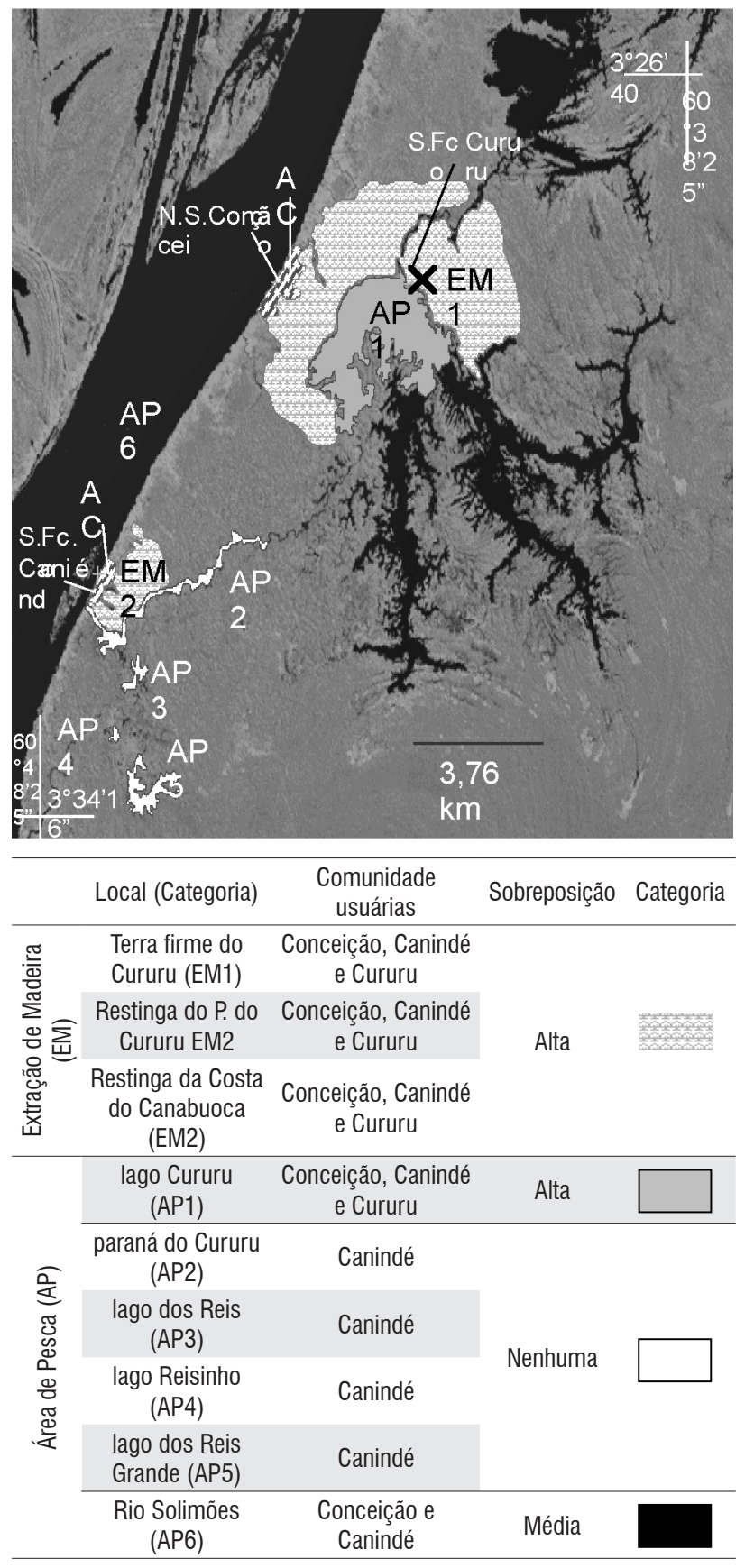

Figura 5 - Espacialização no Sistema Aberto do Cururu da extração de madeira e peixe praticadas pelas comunidades Conceição, Cururu e Canindé. Manacapuru. AM. FONTE CARTOGRÁFICA: Imagem Jers-1-SAR; Maio Julho 1996 (copyright 1992-1998 by NASDAMITI), Base cartográfica Instituto de Proteção do Amazonas.

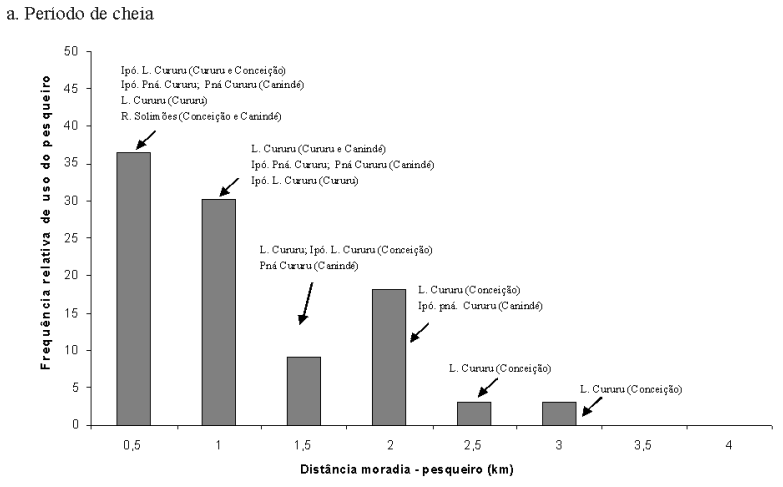

b. Período de seca

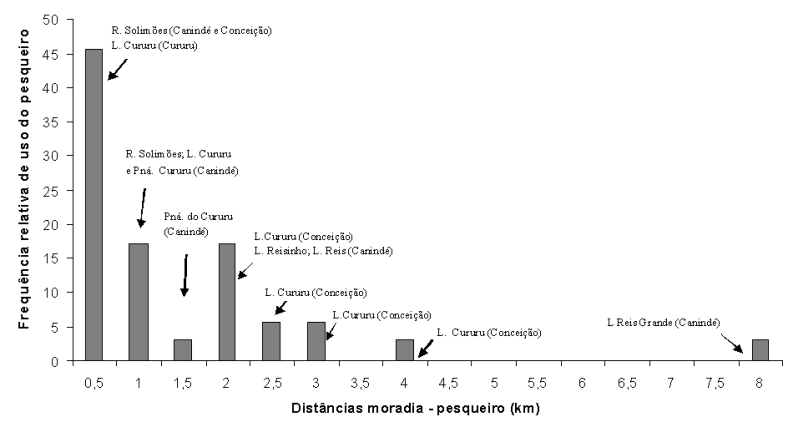

Figura 6 - Freqüência de relativa de uso dos pesqueiros em relação à distâncias percorridas pelos pescadores das comunidades: Canindé, Conceição e Cururu até os pesqueiros: lago (L.) do Cururu, Paraná (Pná.) do Cururu, rio $(\mathrm{R})$ Solimões, lago dos Reis, Reisinho e Reis Grande, no período de (a) cheia e (b) seca.

grau de conhecimento e de participação dos comunitários na elaboração e monitoramento dos mesmos. Uma forte participação e organização política institucional também foram observadas pela presença de quatro entidades representativas a Associação Comunitária; a dos Produtores Rurais; a dos Agentes de Desenvolvimento Sustentável do Cururu; e a Religiosa tanto católica quanto evangélica (Tabela 3).

\section{DISCUSSÃO}

Segundo Diegues (2001), além dos espaços de uso comum, existem outros locais apropriados individualmente, como o lugar de habitação, quintal, área de cultivo, nos quais subsistem arranjos que são permeados por uma teia de relações de parentesco, de compadrio, de ajuda mútua, de normas e valores sociais que privilegiam a solidariedade intragrupal. No presente trabalho, a territorialidade foi abordada dentro da perspectiva do investimento, tanto em termos de jornada de trabalho como do retorno produtivo e econômico da exploração, implicando a uso, controle e defesa do território. Neste sentido, a disposição espacial das comunidades é fundamental para entender, entre outras questōes, a disponibilidade e formas de uso dos recursos naturais. Foi verificado que as comunidades estudadas não são diferentes 
Tabela 3 - Caracterização das relações sociais.

\begin{tabular}{|c|c|c|c|c|c|}
\hline 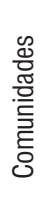 & 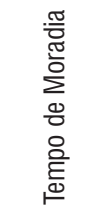 & 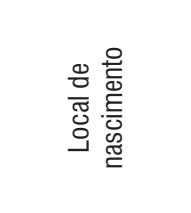 & 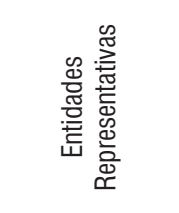 & 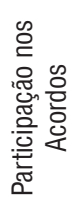 & $\begin{array}{l}\text { 疍 } \\
\text { 亭 }\end{array}$ \\
\hline 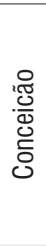 & 36 anos & $\begin{array}{c}12 \% \\
\text { Na própria } \\
\text { comunidade }\end{array}$ & $\begin{array}{l}\text { Associação } \\
\text { comunitária, } \\
\text { religiosa e } \\
\text { ADESC }\end{array}$ & $75 \%$ & $\begin{array}{c}\text { Não } \\
\text { cumprimento } \\
\text { dos Acordos } \\
\text { de uso } \\
\text { Integrado } \\
\text { dos } \\
\text { Recursos }\end{array}$ \\
\hline 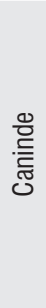 & 16 anos & $\begin{array}{c}24 \% \\
\text { Outro município } \\
\text { fora de } \\
\text { Manacapuru }\end{array}$ & $\begin{array}{l}\text { Associação } \\
\text { comunitária, } \\
\text { dos produtores } \\
\text { Rurais e } \\
\text { religiosa. }\end{array}$ & $68 \%$ & $\begin{array}{c}\text { Não } \\
\text { cumprimento } \\
\text { dos Acordos } \\
\text { de uso } \\
\text { Integrado } \\
\text { dos } \\
\text { Recursos e } \\
\text { apropriação } \\
\text { de recursos }\end{array}$ \\
\hline 疍 & 30 anos & $\begin{array}{c}24 \% \\
\text { Comunidades } \\
\text { de Manacapuru, } \\
\text { fora da área de } \\
\text { estudo }\end{array}$ & $\begin{array}{l}\text { Associação } \\
\text { comunitária, } \\
\text { religiosa e } \\
\text { ADESC. }\end{array}$ & $90 \%$ & $\begin{array}{c}\text { Não } \\
\text { cumprimento } \\
\text { dos Acordos } \\
\text { de uso } \\
\text { Integrado } \\
\text { dos } \\
\text { Recursos. }\end{array}$ \\
\hline
\end{tabular}

das populaçôes ribeirinhas caracterizadas por Meggers (1977) e Moran (1990) e denominadas por Furtado (1993) de "polivalentes". Estes autores demonstram a adaptabilidade às diferentes formas de uso do sistema e de seus recursos naturais, reflete na diversidade de atividades extrativas e produtivas de acordo com a disponibilidade de recursos e ambientes, fato que está relacionado com a sazonalidade de subida e descida das águas (Fabré \& Ribeiro, 2003).

\section{AGRICULTURA}

Na comunidade São Francisco do Cururu a agricultura é realizada em ambiente de terra firme às margens do lago Cururu, onde a atividade é praticada na parte mais alta do terreno, e apresenta produtividade e rendimento econômico menor em relação às comunidades da "Costa", que utilizam a restinga do Canabuoca, à margem do rio Solimôes. O alto rendimento produtivo e econômico observado nas comunidades da Costa pode ser explicado pelo tamanho da área plantada e a alta diversidade cultivada. Contudo, o plantio de malva que tem, segundo declaraçôes dos produtores, alto retorno econômico, revela uma tendência à monocultura, que é incentivada localmente pelo sistema de comercialização instituídos nas comunidades da Costa. Esses dados são corroborados por Moraes et al. (2002) que calcularam o Valor Bruto da Produção Agrícola (VBP) em US\$ 417,93 por mês durante uma ano (entre 2000 a 2001) para a comunidade São Francisco do Canindé, dedicada principalmente ao cultivo de malva. Esse VBP supera significativamente o da comunidade Nossa Senhora da Conceição (US\$ 180,48/mês) que pouco se dedica à cultura de malva. Parente (2003) verificou que na comunidade São Francisco do Canindé o tamanho das áreas de plantio da malva é bem maior, em média, 3,3 ha por produtor, sendo o carro-chefe da produção dos agricultores desta comunidade, assim como uma destacada eficiência na comercialização.

Dessa forma, pode-se dizer sobre a renda oriunda da agricultura, que os fatores: quantidade produzida, tamanho da área, número de pessoas envolvidas, espécies produzidas, tipo de ambiente explorado, condiçôes de mercado e sistema de comercialização e a distância da comunidade ao plantio são os fatores determinantes nos rendimentos produtivos e econômicos da atividade agrícola. Por outro lado, conclui-se que a agricultura não é uma atividade geradora de conflitos oriundos da defesa de territórios, uma vez que as áreas de plantio são pré-estabelecidas e reconhecidas pelos membros das comunidades como terrenos particulares, apesar de que as áreas de várzea serem de propriedade da União. Este contexto é diferente do observado por Batista et al. (1998), no Baixo Solimões nas Costas do Pesqueiro, Marimba, Aruanã e Paciência, onde há conflitos entre agricultores e pecuaristas, visto que ocorre invasão das áreas de cultivo pelo gado. Os agricultores alegam que o gado prejudica o bom desempenho das áreas destinadas à agricultura, como resultados são gerados conflitos de uso com as práticas de bovinocultura.

\section{PESCA}

$\mathrm{Na}$ atividade pesqueira, os diferentes ambientes utilizados durante a seca e a cheia podem ser relacionados com a produtividade e localização do pesqueiro, que determinará a distância a ser percorrida pelo pescador e, conseqüentemente, no tempo investido na produção. Segundo Costa Neto (2001) o conhecimento dos pescadores a cerca de onde e quando determinado recurso ou fenômeno ocorre permite que eles otimizem a apropriação dos recursos, baseados na distribuição e abundância de determinadas espécies.

Na Costa do Canabuoca, Batista e Fabré (2003) observaram que o ambiente lago foi o mais utilizado por todas as comunidades. Na comunidade Nossa Senhora da Conceição a maior freqüência relativa foi de 28 para os paranás e na São Francisco do Canindé a maior foi de 50 para os lagos. Os resultados do presente trabalho indicam que a produtividade do sistema lacustre pode ser explicada pela interação dos fatores: tipo de ambiente explorado, tempo de investimento e tipo de apetrecho utilizado para a captura. Estes resultados são corroborados por Seixas e Begossi (1998) que mencionam que 
o comportamento territorial pesqueiro pode estar relacionado à mobilidade de recursos e aparelhos, propósitos da pesca (subsistência, comércio e recreação), densidade de pescadores, diversidade de recursos, diversidade de pontos de pesca e segredos sobre a qualidade do ponto de pesca.

Garcez (2000) e posteriormente Batista \& Fabré (2003) na mesma área de pesquisa do presente trabalho, destacam que a organização espacial de uso é estabelecida conforme a disponibilidade e acessibilidade ao ambiente aquático e seus recursos e que esta organização estaria diretamente relacionada à distância que o pescador tem que percorrer para chegar ao pesqueiro, otimizando assim sua jornada de trabalho. Foi comprovado que locais mais distantes, como o lago Cururu, são explorados preferencialmente por duas das três comunidades estudadas, e conforme Batista e Fabré (2003) mais 4 comunidades do sistema Cururu usam este lago. $\mathrm{O}$ resultado é a ocorrência de forte competição, principalmente pelo micro-ambiente denominado localmente como Poço ${ }^{2}$, constituindo-se em centro de conflito entre a Comunidade São Francisco do Cururu (distante a menos de 0,1 km desse celeiro) e as comunidades usuárias do lago localizadas na costa, como é o caso da comunidade Nossa Senhora da Conceição (distante em média $2 \mathrm{~km}$ ). Dentro deste contexto, foi observado a existência de conflitos e a sobreposição de áreas de exploração, logo uma forte territorialidade exercido pela comunidade São Francisco do Cururu, que de fato trata este celeiro como de "propriedade privada", pois segundo relatos de comunitários da área, os mesmos inibem a entrada de pescadores de outras comunidades, principalmente durante a seca, postura que gerou conflitos com as demais comunidades da Costa.

Fabré et al. (2006) discutem amplamente a territorialidade, estudando os mecanismos de apropriação no sistema aberto do Cururu e observaram que nas áreas mais próximas às moradias há uma maior intensidade de apropriação, defesa e cuidado dos recursos naturais, e estabeleceram um paralelo entre essas áreas e o conceito de "lugar", "homelad" ou moradia de Raffestin (1993). Cada grupo social que integra o sistema, localmente reconhecido como comunidade, exerce uma forma de propriedade do território, a qual será mais específica conforme aumenta o grau de dependência individual ou coletiva dos recursos naturais nele contidos. O "Poço", além de ser um celeiro de uso comum do sistema, configura a moradia de um dos grupos sociais da área, a comunidade localizada a menos de $0,5 \mathrm{~km}$, a qual depende quase que exclusivamente deste celeiro. Os restantes grupos sociais do sistema exploram o que eles entendem como celeiro de uso comum: o Poço, o resultado é a configuração de um centro de conflito socioambiental.
A comunidade que tem o Poço como sua moradia e assume que essa área do lago é de propriedade da família que lidera esse grupo social, adquire um discurso preservacionista e atua como fiscal local controlando e proibindo o acesso de outras comunidades.

De acordo com Begossi (2004) dominar ou se apropriar de um território envolve custos, de tal forma que o recurso pleiteado deve compensar os custos e benefícios da manutenção, que implicam numa inter-relação entre distribuição e disponibilidade do recurso e organização social das comunidades.

A preferência por ambiente de refúgio para as espécies de peixe (poço) foi observada por Amaral (2004) em populações indígenas do rio Breu no Peru, no entanto, esse autor não cita sobreposição de uso pelas comunidades, uma vez que elas utilizavam poços diferentes, de acordo com a proximidade e a espécie de preferência. Neste caso, acredita-se que a maior disponibilidade desse tipo de celeiro evita conflitos.

Begossi (2001), também observou que na ilha de Búzios os locais mais próximos mostram alta freqüência de uso em relação aos locais mais distantes, porém os pescadores que utilizam locais mais longínquos investiam mais tempo de pesca e retornando com grandes capturas. Já na Ilha Grande e na Ilha de Sepetiba, os pescadores preferem locais mais próximos a suas residências. Apesar disso, a autora cita uma tendência para gastar mais tempo pescando, para ganhar mais produção, em locais que são mais distantes.

\section{MADEIRA}

Não foi identificada uma relação direta entre distância e rendimento produtivo da extração madeireira, isto pode ser explicado pela baixa quantidade explorada e o destino da produção, já que esse recurso é utilizado somente para construção civil e naval (moradias, canoas, remos e outros), portanto, aparentemente não representa uma atividade forte na geração de renda local. Parente (2003) observou que a exploração madeireira na Costa do Canabuoca é realizada com fins lucrativos. Esta discrepância pode ser explicada pelo impacto do Acordo de Uso Integrado, que foi legitimado depois dos levantamentos realizados por Parente, visto que o Acordo restringe a exploração de madeira aos comunitários que registrem perante o Conselho Local de Gestão Ambiental um plano de manejo comunitário para esse tipo de extrativismo.

No presente trabalho não foram registrados conflitos em relação à extração de madeira, embora se observe sobreposição nas áreas de exploração, o que implica, a princípio, que esta atividade não revela territorialidade. Isto pode ser atribuído

2 Poço: micro-ambiente característico dos lagos de origem fluvial da Amazônia cuja fisiografia propicia sua integridade aquática ainda durante o período de seca, fato que Ihes confere alta produtividade pesqueira (Ribeiro \& Fabré, 2003). 
ao baixo número de pessoas que se dedicam a esta atividade e as grandes extensões territoriais, tanto nos ambientes de várzea quanto nos ambientes de terra firme disponíveis para a extração. De tal forma, a disponibilidade e acessibilidade atende a demanda pelo recurso gerada por uma baixa densidade de madeireiros atuantes no sistema.

\section{RELAÇÕES SOCIAIS, INSTRUMENTO DE GESTÃO E REPRESENTATIVIDADE SOCIAL}

A mobilidade espacial é um fator preponderante para o estabelecimento e cumprimento de normas de uso dos recursos, principalmente porque está ligada à capacidade de reprodução social. Portanto, a baixa taxa de migração observada nestas comunidades pode ser explicada pela disponibilidade de recursos suficientes para sua reprodução, sendo que este fato também traz apropriação local dos recursos de uso comum, como o peixe. Hoffmann (2004), destaca que o tempo de moradia em um local promove conhecimentos empíricos da realidade local trazendo domínio dos grupos locais dos melhores locais para extrair os recursos, gerando assim competição e conflitos. Isto pode ser observado, na área estudada, de forma especial na atividade de pesca, por ser esta a principal fonte de subsistência e geração de renda para estas comunidades. As entidades locais estabelecidas formam as associaçôes, nas quais um grupo organizado é escolhido pela própria comunidade para organizar e estabelecer instrumentos de barganha para os associados e também para gerir conflitos (Pereira, 1999; McDaniel, 1997; Berkes, 1995; Ribeiro \& Fabré, 2003).

Muitos estudos (McGrath et al., 1996; McDaniel, 1997; Berkes, 1995; Berkes \& Henley, 1997; Begossi, 1995; Hanna, 1998; Begossi, 2001; Pereira, 1999) têm detectado a existência de normas locais para a pesca, estabelecidas pelos próprios usuários dos recursos, importantes para a manutenção dos sistemas e conservação dos ecossistemas locais. Mais uma vez essas normas são frutos do conhecimento local e da territorialidade das comunidades e representam as regras de uso intrínsecas, que de fato, evitam o colapso dos recursos, se contrapondo ao princípio da tragédia dos comuns de Hardin (Fenny et al.,1990 apud Diegues \& Moreira, 2001), o qual afirma que a liberdade para explorar recursos comuns gera ruína de todos e que a única forma de evitar total destruição seria privatizar ou definir como propriedades públicas para as quais os direitos de uso seriam definidos. $\mathrm{O}$ que não condiz com a realidade local, uma vez que os usuários estabelecem regras de uso e as legalizaram com a elaboração do Acordo de Uso Integrado dos Recursos Naturais. Fato este que corrobora com as conclusões de Fenny et al. (2001) apud. Moreira \& Diegues (2001), avaliando a negligência do autor ao importante papel dos arranjos institucionais locais e os fatores culturais para a geração de exclusão e regulação de uso.
O Acordo surgiu pela demanda dos comunitários da Costa do Canabuoca (usuários do Sistema lacustre Cururu) que mobilizados pela dificuldade de acesso aos celeiros da área e em parceria com o Programa PYRÁ da Universidade Federal do Amazonas e Instituto Brasileiro de Meio Ambiente e dos Recursos Naturais Renováveis - IBAMA/AM, no intuito de minimizar os conflitos pelo peixe no Sistema Cururu, estabeleceram os "Acordos de uso integrado dos recursos naturais". O qual não somente envolveu os recursos pesqueiros, mas também regras para o uso de agrotóxicos, da água e da floresta. Durante o ano de 2000 a 2002 foram realizadas reuniōes comunitárias, cursos de capacitação sobre legislação, gestão ambiental, saúde, agrotóxicos, ecologia da Amazônia, entre outros, conduzidos pelo PYRÁ junto a seus parceiros em dois sistemas lacustres da região o Cururu e o Jacaré. Essas atividades culminaram com a formalização perante o IBAMA - AM de dois Acordos, Portarias: $\mathrm{n}^{\circ} 11 \mathrm{e}$ $\mathrm{n}^{\mathrm{o}} 12$ de 2002. Apesar das discussões participativas e formação comunitária continuada, para estabelecimento das regras de uso legalizadas no Acordo, ainda há conflitos entre as 12 comunidades signatárias.

Nesse sentido, este modelo ou qualquer modelo de gestão revela a necessidade de uma constante intervenção de agentes indutores governamentais e não governamentais para a manutenção da representatividade e articulação dos grupos sociais, buscando a minimização de conflitos e melhorar a qualidade de vida dos moradores locais. A esse modelo de gestão, a administração comunitária e intervenção de agentes externos, principalmente o governo, chama-se cogestão. Dessa forma, pensar em gestão não implica somente empoderar e instrumentalizar os grupos sociais locais, paralelamente devem ser construídos e articulados uma rede social e institucional que venha servir de sustentação continuada a estes novos modelos que amplamente vem-se multiplicando na Amazônia.

\section{BIBLIOGRAFIA CITADA}

Batista, V.S.; Inhamus, A.J.; Freitas, C.E.C.; Freire-Brasil, D. 1998. Characterization of the fishery in rivers communities in the low Solimões /high Amazon region. Fisheries management and ecology. Manaus, AM. pp.419-435

Begossi, A.1995. Fishing spots and sea tenure: incipient forms of local management in Atlantic Forest Coastal communities. Human Ecology, vol.23, n³.

Begossi, A. 2001. Mapping spots: fishing areas or territories among islanders of the Atlantic Forest (Brasil). Reg Environ Change. Vol.2. pp.1-12.

Begossi, A. 2004. Áreas, pontos de pesca, pesqueiros e territórios na pesca artesanal. In: Begossi, A.2004. Ecologia dos pescadores da mata atlântica e da Amazônia. Editora Hucitec. NEPAM/ UNICAMP. NUPAUB/USP. FAPESP. São Paulo. 
Berkes, F. 1995. Community-based management of common property resources. Encyclopedia of Environmental Biology. Vol.1.

Berkes, F. \& Henley, T. 1997. Co-management and tradicional knowledge: Threat or opportunity? Policy Options.

Costa Neto, E. M. 2001. A cultura pesqueira do litoral norte da Bahia: etnoictiologia, desenvolvimento e sustentabilidade. Salvador: EDUFBA; Maceió, EDUFAL. 159p

Diegues, A.C. 2001. O mito moderno da natureza intocada. HUCITEC. São Paulo.

Diegues,A.C. e Moreira,A.C.C. Espaços e Recursos Naturais de Uso Comum.SP. NUPAUD-USP.2001.

Dyson-Hudson, R \& Smith, E.A. 1978. Human Territoriality: an ecological reassessment. American Anthropologist. 80 (1): $21-41$

Fabré, N.N.; Ribeiro, M.O.A.2003. Diversidade Amazônica: Ocupação e uso dos ambientes de várzea: 85-113. In: Ribeiro, M. O. A \& Fabré, N.N., 2003. S.A.S - Sistemas Abertos Sustentáveis: uma alternativa de gestão ambiental da Amazônia. EDUA. Manaus. 243 p.

Fabré, N. N. ; Ribeiro M. O. A. ; Batista, Vandick. Sistemas Abertos Sustentáveis (SAS): Uma alternativa para a gestão ambiental em áreas Rurais. In: VII CONGRESO LATINOAMERICANO DE SOCIOLOGÍA RURAL, 2006, Quito. VII CONGRESO LATINOAMERICANO DE SOCIOLOGÍA RURAL. GT. Pesca. Quito : ALASRU, 2006. v. CDROM. p. 1-15.

Furtado, L.G.1993. Pescadores do rio Amazonas. Um estudo antropológico da pesca ribeirinha numa área Amazônica. Coleção Eduardo Galvão.Museu Emilio Goeldi, BELÉM.486p.

Garcez, D. S. 2000. A pesca dos ribeirinhos em ambientes de várzea de uso comum, Baixo Solimões, Amazônia Central. Dissertação de mestrado. Instituto Nacional de Pesquisas da Amazônia - INPA/ Universidade Federal do Amazonas -UFAM. Amazonas, AM.

Gogard, O. A relação interdisciplinar:problemas e estratégias. In:VIEIRA, P.F. \& WEBER, J.(Orgs). Gestão de recursos Naturais Renováveis e Desenvolvimento - novos desafios para a pesquisa ambiental. São Paulo. Cortez, p. 115-146. 1996.
Hanna, S. 1998. Co-management in small-scale fisheries: creating effective links among stakeholders. International CBNRM Workshop.pp.1-10.

Hoffman,I. 2004. Acess to land and water in the Zamfara Reserve. A case study for the management of common property resources in Pastoral areas in of west Africa. Human Ecology. Vol.32, $\mathrm{n}^{\circ} 1$. pp. 77-105.

Mcdaniel, J.1997. Communal Fisheries Management in the Peruvian Amazon. Human Organization. Vol.56, №2.

Meggers, B. 1977. Amazônia: a ilusão de um paraíso. Editora civilização Brasileira S.A. Rio de Janeiro. 207p.

Moraes, R. P.G. 2002. Indicadores de desenvolvimento integrado na avaliação de potencialidades ecoturísticas em áreas rurais de várzea no município de Manacapuru - Am. Dissertação de mestrado. Centro de Ciências do Ambiente. Universidade Federal do Amazonas.Manaus - Amazonas.

Morán, E. F.1990. A ecologia humana das populaçôes da Amazônia. Editora Vozes. Petrópolis, Rio de Janeiro.367p.

Parente,V.M. 2003. A economia da pequena produção na várzea: sobrevivência das famílias ribeirinhas. In: RIBEIRO, M. O.A. \& FABRE, N.N., 2003. SAS -Sistemas Abertos Sustentáveis: uma alternativa de gestão ambiental na Amazônia. EDUA. Manaus. 243p.

Pereira, H. S. 1999. Common property regimes in Amazonia fisheries. Tese de doutorado. The Pennsylvania State University.

Raffestin, Claude. Por uma Geografia do Poder. São Paulo: Ática, 1993.

Ribeiro, M. O. A. \& FABRÉ, N. N. 2003. S.A.S - Sistemas Abertos Sustentáveis: uma alternativa de gestão ambiental na Amazônia. Edua. Manaus. Amazonas. 243p.

Seixas, C.S.\& Begossi, A. 1998. Do fishers have of fishing grounds at Aventureiro (Ilha Grande, Brazil). The seventh annual conferenceoh the International Association for Study of common property, Vancouver, British Columbia, Canadá.

Recebido em: 06/10/2006

Aceito em: 06/08/2009 
